\title{
Impact of Dietary Pattern on Human Life Quality and Life Expectancy: A Mini-Review
}

\author{
Ceren Gezer* \\ Department of Nutrition and Dietetics, Eastern Mediterranean University, Cyprus
}

*Corresponding author: Ceren Gezer, Department of Nutrition and Dietetics, Faculty of Health Sciences, Eastern Mediterranean University, Famagusta, North Cyprus/Mersin 10, Turkey

Submission: 眥 February 26, 2018; Published: 泚 May 03, 2018

\begin{abstract}
During the lifespan, there are multiple factors influence the longevity including genotype, metabolism, physiology, sociodemographic and environmental factors, nutritional and lifestyle habits. Nutrition during the life time has an effect on the health status. Dietary indexes, certain dietary patterns and dietary guidelines have been used for analysing dietary pattern and life expectancy relationship in many studies. Dietary pattern has an important effect on longevity. The cohort study results indicate that diet quality and Medittarenean diet have potential effects on longevity. The important effects of nutrition on longevity related with quality, quantity, frequency, variety and emotional satisfaction. Therefore, nutritional strategies that provide clear benefits for ageing linked with both physiological and psychological functions to maintain life quality. The aspiration is not only to "live longer" but to "live better," and to maintain optimal qual -ity of life during the later stages of life.
\end{abstract}

Keywords: Dietary pattern; Diet quality; Longevity; Life quality; Lifespan

\section{Introduction}

It is known that a remarkable increase in life expectancy and ageing population increase day by day [1]. During the lifespan, there are multiple factors influence the longevity including genotype, metabolism, physiology, sociodemographic and environmental factors, nutritional and lifestyle habv its. A healthy lifestyle is fundamental in disease prevention and expanding longevity $[2,3]$. Nutrition during the life time has an effect on the health status. Healthy lifestyle is related with reduced chronic disease risk [4]. The prospective cohort study with Chinese women showed that healthy lifestyle factors such as lower central adiposity, physical activity, non-smoking, fruit and vegetable consumption related with total and cause specific mortality [5]. In addition, a multiethnic cohort study results indicated that chronic disease risk index was inversely associated with lifespan [6]. Thus, the studies of lifestyle factors and survival focused on the importance of healthy lifestyle behaviors such as diet quality, non-smoking, and physical activity to get long-term health benefits. The 10 years longitudinal SENECA Study is conducted with 70-75 years old 1091 men and 1109 women in 9 European countries and the results point that smoking, low diet quality and less physical activity is related with the survival. Unhealthy lifestyle includes smoking, low diet quality and less physical activity increased mortality risk three to four fold. While non-smoking and less physical activity increased the mortality risk and delayed breakdown of the health status, diet is not have obvious effect alone. Related with that the lifestyle habit constituents such as nutrition, physical activity and smoking can modify to be healthier could improve the quality of life by delay the morbidity [7-9]. Dietary pattern is the well known important context of a healthy lifestyle and affects mortality. In this paper it is aimed to review the relation between human dietary pattern and life quality-expectancy.

\section{Dietary Pattern}

The studies related with nutrition and life expectancy can generally classified into three types. The first type includes the nutrition related indicators and mortality data. Second type includes population risk rate to support effects of nutrition on morbidity and disease cause mortality. While first type established direct, second type established indirect relation between nutrition and life expectancy. Third type involves regional nutrition level and life expectancy analysis [10]. Dietary indexes, certain dietary patterns and dietary guidelines have been used for analysing dietary pattern and life expectancy relationship in many studies [11].

\section{Diet Quality}

Longer lifespan is associated with obesity, cardiovascular diseases (CVD), type II diabetes, cancer which are nutrition-related chronic diseases [12]. A Nurses Health cohort study showed that greater Alternative Healthy Eating Index-2010 and Alternate Mediterrannean Diet scores in midlife related with healthy ageing [13]. Diet quality is one of the main part of life quality, thus related with longevity. The Diet Quality Index was developed to measure overall dietary patterns, predict chronic disease risk but also 
can used as a predictor of short-term mortality [14,15]. Another longitudinal study with 3328 old men (60-79 years), Healthy Diet Indicator (based on WHO dietary guidelines) and the Elderly Dietary Index (based on a mediterranean dietary pattern) indicated that high diet quality is associated with all-cause mortality [16]. In addition, the longitudinal British Diet and Nutrition Survey with 972 participants (aged $\geq 65$ years) measured the diet quality with three index and while the Healthy Diet Score was not a predictor of mortality, the Recommended Food Score and the Mediterranean Diet Score were related with all-cause mortality [17]. Also, the Breast Cancer Detection Demonstration Project, a prospective cohort study results showed that low diet quality is related with increased mortality risk [18]. In addition, American Cancer Society Cancer Prevention Study II Nutrition Cohort study results indicate that diet quality was related with all cause and all circulatory disease mortality rates [15]. According to results of First National Health and Nutrition Examination Survey (NHANNES)-I low dietary diversity significantly correlates with high mortality risk of both men and women [19]. Another prospective study in Sweden conducted with women, demonstrated that cancer mortality of women who consume high consumption of red meats, refined carbohydrates, sugars, foods involve high saturated and trans fat is higher than women who consume that foods low amount [20]. According to the 16-year follow-up Whitehall II cohort study results, to be avoide from fried and sweet food, processed and red meat, refined grains, and high-fat dairy products is associated with a higher odds of disease-free and highly functional elderly [21]. Also, the prospective study in Europe with 452,717 participants indicated that increased fiber is associated with lower total mortality rate, and as a fiber source cereals-vegetables have effects more than fruits [22].

\section{Mediterranean Diet}

The characteristics of Mediterranean diet is a high intake of vegetables, legumes, fruits, and cereals; a moderate to high intake of fish; high intake of unsaturated lipids, a low to moderate intake of dairy products, a low intake of meat; and a modest intake of wine. Several studies have reported inverse associations with Meditteranean diet and overall mortality [23]. Mediterranean diet was inversely associated with total mortality with 22,043 adults in Greece [24]. The findings of the HALE Project which was conducted between the years of 1988-2000 with 2339 healthy participants aged between 70-90 years indicated that a Mediterranean diet and healthy lifestyle lower all-causes and cause-specific mortality at least 50\% [25]. Moreover, the European Prospective Investigation into Cancer and Nutrition (EPIC)-elderly prospective cohort study conducted with 74,607 participant aged $<60$ years at nine European countries found out the association between Mediterranean diet and lowering overall death rate [23]. Besides that, the cohort study conducted with Dutch women aged 60-69 years found out that a Healthy Traditional Dutch diet, more beneficial than Mediterranean diet for longevity [26]. The study with older Swedish participants showed that Mediterranean dietary patterns including whole grain cereals, foods rich in polyunsaturated fatty acids, and a limited amount of alcohol can increase the longevity in the elderly [27]. Also, it is known that moderate wine consumption, another characteristic of Meditarrenean Diet reduces CVD risk and extend lifespan related with its resveratrol content [28]. In addition, the 12 years follow up study which is conducted with young women aged 30-49 years in Sweden showed that Mediterranean dietary pattern reduces overall and cancer mortality [29]. Furthermore, the cohort EPIC-Spain with 40,622 participants demostrated that olive oil is associated with $26 \%$ reduction of overall mortality and each $10 \mathrm{~g}$ increase of olive oil consumption decreased overall mortality $7 \%$ rates [30]. Besides that the National Institutes of Health diet and health study included 214284 men and 166012 women showed that medittarenean dietary pattern reduced overall, cancer and CVD mortality in United States [31]. The results of meta-analysis of 12 studies indicated that medittarenean diet significantly reduced overall mortality (9\%), mortality from cardiovascular disease (9\%) and cancer mortality (6\%) [32].

\section{Vegeterian Diet}

The results of reviewed data of the six studies indicated that in four studies there was a relation between a very low meat intake and decreased risk of death and the findings from one cohort of healthy adults showed that long-term ( $\geq 2$ decades) vegetarian diet can produce 3.6 years increase in life expectancy [33]. On the other hand, meat consumption was not associated with mortality according to results of NHANNES III which was conducted with 17,611 participants between 1986-2010 [34]. Moreover, according to the position paper of American Dietetic Association a vegetarian diet is related with a lower risk of death ischemic heart disease and the evidence based level is grade I-good [35].

\section{Calorie Restriction}

This term defined as energy restriction without malnutrition. Since the first published research on calorie restriction and extended longevity in rats, many studies conducted with lifespan in a variety of spices including yeast, flies, worms, fish, mice and rats. The calorie restriction studies on mice and rat indicated that delays ageing [36-38]. In addition, studies conducted with Rhesus monkeys as primates evolutionary closer to humans demonstrated that $30 \%$ calorie restricted diet reduces age-related and all-cause mortality [39]. The findings of long term epidemiological study with Okinawans indicated that low calorie intake, little weight gain with age, life-long low body mass index linked with low risk for age related disease mortality and extended lifespan [40]. Therefore, longest-lived people Okinawans live 4 year longer than Americans since their low calories and nutritionally dense traditional diet $[41,42]$. Moreover, longterm human studies data showed that several metabolic adaptations such as of insulin, insulin like growth factor- 1 and interleukin-6, reduction of triodothyronine level and body temperature, oxidative damage, natural genetic variants in nutrient sensing pathways and alterations in autonomic function reduce the risk of type 2 diabetes, hypertension, cardiovascular disease and cancer thus extend the life span [43-47]. Hence, different responses of organisims to dietary restriction need to 
design new or improved further studies to understand metabolic, molecular pathways related with calorie restriction and longevity.

\section{Conclusion}

To conclude, while the complicated interactions between caloric intake, dietary pattern and genotype in relation with longevity are difficult to study in mammals. The findings concur that healthy lifestyle behaviours, which includes a healthy nutrition, moderate physical activity, and non-smoking, increased life expectancy. The important effects of nutrition on longevity related with quality, quantity, frequency, variety and emotional satisfaction. Therefore, nutritional strategies that provide clear benefits for ageing linked with both physiological and psychological functions to maintain life quality. The aspiration is not only to "live longer" but to "live better," and to maintain optimal qual $\rightarrow$ ity of life during the later stages of life. Thus, healthy nutrition and other lifestyle behaviours are crucial for this aim. Moreover, a holistic view on ageing and nutrition could not be only related with diet and lowering morbidity, leads to mortality but also could be related with healthy ageing without morbidity risk.

\section{References}

1. World Health Organisation (2015) World report on ageing and health World Health Organisation Press, Switzerland.

2. Slawson DL, Fitzgerald N, Morgan KT (2013) Position of the academy of nutrition and dietetics: The role of nutrition in health promotion and chronic disease prevention. Journal of Academy of Nutrition and Dietetics 113(7): 972-979.

3. Chrysohoou C, Stefanadis C (2013) Longevity and diet. Myth or pragmatism? Maturitas 76(4): 303-307.

4. World Health Organisation (2002) Globalization, diets and non communicable diseases. World Health Organisation Press, Switzerland.

5. Nechuta SJ, Shu XO, Li HL, Yang G, Xiang YB, et al. (2010) Combined impact of lifestyle-related factors on total and cause-specific mortality among Chinese women: Prospective cohort study. Plos Medicine 7(9): $1-11$.

6. Meng L, Maskarinec G, Lee J, Kolonel LN (1999) Lifestyle factors and chronic diseases: Application of a composite risk index. Prev Med 29(4): 296-304.

7. Nies AH, Groot LCPGM, Burema J, Cruz JAA, Osler M et al. (2002) Dietary quality and lifestyle factors in relation to 10-Year mortality in older Europeans. Am J Epidemiol 156(10): 962-968.

8. Nies AH, Groot LCPGM, Staveren WA (2003) Dietary quality, lifestyle factors and healthy ageing in Europe: the SENECA study. Age Ageing 32: 427-434.

9. Nies AH, Groot LCPGM, Staveren WA (2003) Relation of dietary quality, physical activity, and smoking habits to 10 -year changes in health status in older Europeans in the SENECA Study. Am J Public Health 93(2): 318323.

10. Zheng XY, Hn YL, Guo C, Zhang L, Qiu Y et al. (2014) Progress in research of nutrition and life expectancy. Biomed Environ Sci 27(3): 155-161.

11. Hu FB (2002) Dietary pattern analysis: a new direction in nutritiona epidemiology. Curr Opin Lipidol 13(1): 3-9.

12. Vallinas MG, Castejon MG, Casado AR, de Molina AR (2013) Dietary phytochemicals in cancer prevention and therapy: A complementary approach with promising perspectives. Nut Rev 71(9): 585-599.
13. Samieri C, Sun Q, Townsend MK, Chiuve SE, Okereke OI, et al. (2013) The relation of midlife diet to healthy aging: a cohort study. Ann Intern Med 159(9): 584-591.

14. Kim S, Haines PS, Riz AMS and Popkin BM (2003) The Diet Quality Index-International (DQI-I) provides an effective tool for cross-national comparison of diet quality as illustrated by China and the United States. J Nutr 133(11): 3476-3484.

15. Seymour JD, Calle EE, Flagg EW, Coates RJ, Ford ES et al. (2003) Diet quality index as a predictor of short-term mortality in the American Cancer Society Cancer Prevention Study II Nutrition Cohort. Am J Epidemiol 157(11): 980-988.

16. Atkins JL, Whincup PH, Morris RW, Lennon LT, Papacosta 0 et al. (2014) High diet quality is associated with a lower risk of cardiovascular disease and all-cause mortality in older men. J Nutri 144(5): 673-680.

17. McNaughton SA, Chris J, Bates CJ, Mishra GD (2012) Diet quality is associated with all-cause mortality in adults aged 65 years and older. J Nutri 142(2): 320-325

18. Kant AK, Schatzkin A, Graubard BI, Schairer C (2000) A prospective study of diet quality and mortality in women. JAMA 283(16): 2109-2115.

19. Kant AK, Schatzkin A, Harris TB, Zeigler RG, Block G (1993) Dietary diversity and subsequent mortality in the First National Health and Nutrition Examination Survey epidemiologic follow-up study. Am J Clin Nutr 57(3): 434-440.

20. Michels KB, Wolk A (2002) A prospective study of variety of healthy foods and mortality in women. Int J Epidemiol 31(4): 847-854.

21. Akbaraly T, Sabia S, Johnson GH, Tabak AG, Shipley MJ, et al. (2013) Does overall diet in midlife predict future aging phenotypes? A cohort study. Am J Med 126(5): 411-419.

22. Chuang SC, Norat T, Murphy N, Olsen A, Tjønneland A, et al. (2012) Fiber intake and total cause-specific mortality in the European prospective investigation into cancer and nutrition cohort. Am J Clin Nutr 96(1): 164174 .

23. Trichopoulou A, Orfanos P, Norat T, Mesquita BB, Ocké M, et al. (2005) Modified Mediterranean diet and survival: EPIC-elderly prospective cohort study. BMJ 330(7498): 991.

24. Trichopoulou A, Costacou T, Christina BC, Trichopoulos D (2003) Adherence to a Mediterranean diet and survival in a Greek population. N Engl J Med 348(26): 2599-2608.

25. Knoops KTB, Groot LCPGM, Kromhout D, Perrin AE, Varela OM, et al. (2004) Mediterranean diet, lifestyle factors, and 10-year mortality in elderly European men and women. JAMA 292(12): 1433-1439.

26. Waijers PMCM, Ocké MC, Rossum CTM, Peeters PHM, Bamia C, et al. (2006) Dietary patterns and survival in older Dutch women. Am J Clin Nutr 83(5): 1170-1176.

27. Tognon G, Rothenberg E, Eiben G, Sundh V, Winkvist A (2011) Does the Mediterranean diet predict longevity in the elderly? A Swedish perspective. Age 33(3): 439-450.

28. Giacosa A, Barale R, Bavaresco L, Faliva MA, Gerbi V, et al. (2016) Mediterranean way of drinking and longevity. Crit Rev Food Sci Nutr 56(4): 635-640.

29. Lagiou P, Trichopoulos D, Sandin S, Logiou A, Mucci L, et al. (2006) Mediterranean dietary pattern and mortality among young women: a cohort study in Sweden. Br J Nutr 96(2): 384-392.

30. Buckland G, Mayen AL, Agudo A, Travier N, Navarro C, et al. (2012) Olive oil intake and mortality within the Spanish population (EPIC-Spain). Am J Clin Nutr 96(1): 142-149.

31. Mitrou PN, Kipnis V, Thiébaut ACM, Reedy J, Subar AF, et al. (2007) Mediterranean dietary pattern and prediction of all-cause mortality in a US population. Arch Intern Med 167(22): 2461-2468. 
32. Sofi F, Cesari F, Abbate R, Gensini GF, Casini A (2008) Adherence to medittarenean diet and health status: meta-analysis. BMJ 337: a1344-a1350.

33. Singh PN, Sabaté J, Fraser GE (2003) Does low meat consumption increase life expectancy in humans? Am J Clin Nutr 78(3): 526S-532S.

34. Kappeler R, Eichholzer M, Rohrmann S (2013) Meat consumption and diet quality and mortality in NHANES III. Eur J Clin Nutr 67(6): 598-606.

35. Craig WJ, Mangels AR (2009) Position of the American dietetic association: Vegeterian diets. J Am Diet Assoc 109(7): 1266-1282

36. Heilbronn LK, Eric RE (2003) Calorie restriction and aging: review of the literature and implications for studies in humans. Am J Clin Nutr 78(3): 361-369.

37. Holloszy JO, Fontana L (2007) Calorie restriction in humans. Exp Gerontol 42(8): 709-712.

38. Fontana L (2009) The scientific basis of caloric restriction leading to longer life. Curr Opin Gastroenterol 25(2): 144-150.

39. Colman RJ, Beasley TM, Kemnitz JW, Johnson SC, Richard WR, et al. (2014) Caloric restriction reduces age-related and all-cause mortality in rhesus monkeys. Nat Commun 5: 3557-3561.

40. Willcox BJ, Willcox DC, Todoriki H, Fujiyoshi A, Yano K, et al. (2007) Caloric restriction, the traditional Okinawan diet, and healthy aging: the diet of the world's longest-lived people and its potential impact on morbidity and life span. Ann N Y Acad Sci 1114: 434-455.
41. Willcox DC, Scapagnini G, Willcox BJ (2014) Healthy aging diets other than the Mediterranean: A focus on the Okinawan diet. Mech Ageing Dev 136: $148-162$.

42. Everitt AV, Heilbronn LK, Morris JB, Borg HMB, Merry BJ, et al. (2010) Conclusion: Human calorie restriction and anti-geing therapy. Arthur VE, Suresh IS, David G, Rafael C (Eds.), Calorie restriction, aging and longevity, Springer, London,UK, pp. 311-318.

43. Meyer TE, Kovács SJ, Ehsani AA, Klein S, Holloszy JO, et al. (2006) Longterm caloric restriction ameliorates the decline in diastolic function in humans. J Am Coll Cardiol 47(2): 398-402.

44. Fontana L, Prtridge L and Longo VD (2010) Extending healthy life spanfrom yeast to human. Science 328(5967): 321-326.

45. Mercken EM, Crosby SD, Lamming DW, JeBailey L, Walker KS, et al (2013) Calorie restriction in humans inhibits the PI3K/AKT pathway and induces a younger transcription profile. Aging Cell 12(4): 645-651.

46. Rizza W, Veronese N, Fontana L (2014) What are the roles of calorie restriction and diet quality in promoting healthy longevity? Ageing Res Rev 13: 38-45.

47. Stein PK, Soare A, Meyer TE, Cangemi R, Holloszy JO et al. (2012) Caloric restriction may reverse age-related autonomic decline in humans. Aging Cell 11(4): 644-650.

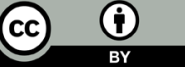

Creative Commons Attribution 4.0 International License

For possible submissions Click Here

\section{Submit Article}

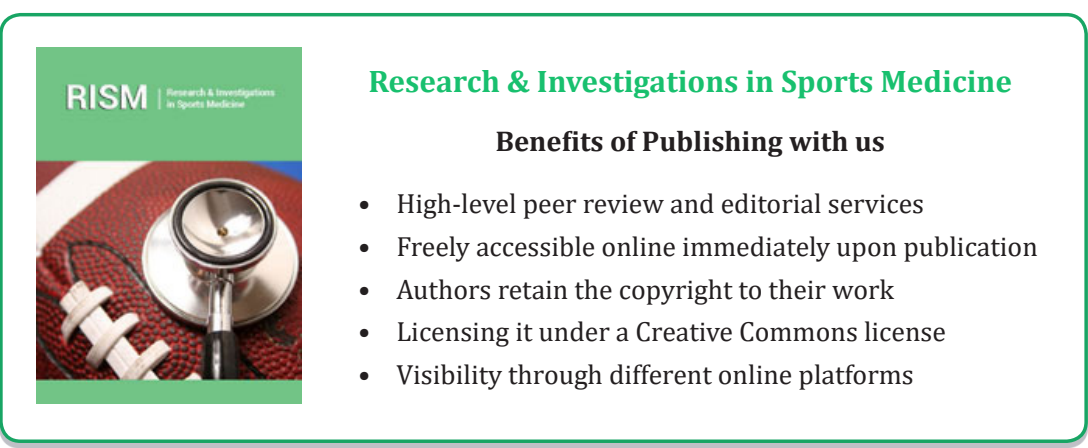

